\title{
PROGRAMAS DE COMPLIANCE E A RESPONSABILIDADE \\ DA EMPRESA NA FASE DE PÓS-CONSUMO DE LIXO \\ ELETRÔNICO
}

\author{
Isabela Moreira do Nascimento Domingos ${ }^{1}$ \\ Pontifícia Universidade Católica do Paraná (PUC-PR) \\ Luiz Alberto Blanchet ${ }^{2}$ \\ Pontifícia Universidade Católica do Paraná (PUC-PR)
}

\section{RESUMO}

O compliance ambiental é um instrumento de inegável relevância e efetividade no cumprimento da Política Nacional de Resíduos Sólidos (PNRS) implementada pela Lei n. 12.305/10, em especial, no tratamento de resíduos eletrônicos no pós-consumo. Assim, o estudo se torna necessário tendo em vista que as sanções criminais e aplicação de multa não são capazes de restabelecer o equilíbrio do meio ambiente. Com base na Agenda 2030, as empresas devem adotar políticas de desenvolvimento sustentável. Os programas de compliance atuam anteriormente à prática do delito, pela fiscalização de forma top-down e pela implementação de uma nova cultura ética de responsabilidade socioambiental das organizações, que envolvem o respeito ao ser humano e ao meio ambiente. Utiliza-se do método hipotético-dedutivo, com o apoio da análise jurisprudencial, bibliográfica e reportagens acerca do lixo eletrônico. Foi possível deduzir que a relevância do tema torna a prática do compliance obrigatória para

1 Mestranda bolsista CAPES) em Direito Econômico e Socioambiental pela PUC-PR. Especialista em Direito Penal Econômico pela Fundação Escola do Ministério Público do Estado do Paraná (FEMPAR). Graduada em Direito pelo Centro Universitário Curitiba (Unicuritiba). Integrante do Núcleo de Pesquisas em Políticas Públicas e Desenvolvimento Humano (NUPED), do Núcleo de Estudos de Pesquisas em Tributação, Complexidade e Desenvolvimento e colaboradora do TAXPuc (CNPq/PUCPR). Associada do Conselho Nacional de Pesquisa e Pós-Graduação em Direito (CONPEDI). Advogada. E-mail: isabela.mdomingos@gmail.com

2 Doutor e Mestre em Direito pela Universidade Federal do Paraná (UFPR). Professor titular dos cursos de Doutorado, Mestrado, Especialização e Graduação da PUC-PR. Membro catedrático da Academia Brasileira de Direito Constitucional (ABDConst), membro do Instituto dos Advogados do Paraná - IAP. Advogado. ORCID: https://orcid.org/0000-0003-1163-0342 / E-mail: blanchet@ blanchet.adv.br 
o cumprimento das obrigações socioambientais, evitando denúncias junto a órgãos técnicos ambientais e à persecução criminal, que podem levar à desvalorização da marca e até mesmo à desconsideração da personalidade jurídica.

Palavras-chave: compliance; desenvolvimento sustentável; logística reversa; resíduo eletrônico.

\section{COMPLIANCE PROGRAMS AND COMPANY'S RESPONSIBILITY OF POST-CONSUMPTION PHSE OF ELECTRONIC WASTE}

\section{ABSTRACT}

The environmental compliance is an instrument of undeniable relevance and effectiveness in complying with the National Solid Waste Policy (PNRS) implemented by Law $n .12 .305 / 10$, especially for the treatment of electronic waste in the post-consumption. Thus, the study becomes necessary in view that criminal sanctions and impose fine enforcement are not able to restore the balance of the environment. Based on Agenda 2030, companies must adopt sustainable development policies. The compliance programs work prior to the practice of crime, through top-down supervision and the implementation of a new ethical culture of social and environmental responsibility of organizations, which involve respect for the human being and the environment. The hypothetical-deductive method is used with the support of the jurisprudential, bibliographical analysis and reports on the electronic waste. It was possible to deduce that the relevance of the topic makes compliance practice mandatory for the fulfilment of social and environmental obligations, avoiding denunciations with environmental technical agencies and criminal prosecution, which may lead to brand devaluation and even disregard of legal personality.

Keywords: environmental sustainability; electronic waste; reverse logistics; compliance. 


\section{INTRODUÇÃO}

Em um mundo cada vez mais globalizado, as corporações passam a perceber e reconhecer a importância da contenção do risco da atividade empresarial em face do meio ambiente. Nesta linha, o programa de compliance se torna um mecanismo eficaz para o cumprimento de leis, normas e políticas de transparência nacionais e internacionais.

Como já previam Beck, Giddens e Lash (2012), a sociedade de risco impulsionada pela revolução industrial e o capitalismo desenfreado, fez com que parte da população vivesse em mundo sujeito a catástrofes e desiquilíbrios ambientais, advindos da sociologia do risco.

$\mathrm{O}$ agravamento de incertezas e probabilidades trágicas desde o acidente nuclear de Chernobyl (1986), requer que o Estado e demais atores sociais identifiquem as falhas dos sistemas de produção e exploração para a implementação de uma nova cultura sustentável.

Nesse sentido, a pesquisa apresenta os programas de compliance como uma ferramenta preventiva e complementar às vias tradicionais da punição administrativa e criminal ${ }^{3}$, que pode ser implementado antes da prática da infração, permitindo que a empresa e o Estado tenham melhor controle dos riscos ambientais.

A metodologia escolhida para a produção desta pesquisa foi a hipotética dedutiva com consulta a doutrina, legislação ambiental e reportagens acerca do tema, para posterior confirmação das hipóteses ora abordadas. $\mathrm{O}$ trabalho foi dividido em três sessões, sendo a primeira parte direcionada à introdução do tema e aos objetivos da pesquisa. No segundo ponto, serão abordadas as práticas sustentáveis de desenvolvimento socioeconômico com a participação não apenas do Estado, mas da comunidade e empresa, na construção desse novo processo de desenvolvimento sustentável.

Já na terceira sessão do texto, pretende-se discutir os saberes necessários para implementação dos programas de compliance ambiental e a responsabilidade da empresa na logística reversa dos produtos eletrônicos, com base na Política Nacional de Resíduos Sólidos (PNRS).

\footnotetext{
3 Desta feita, quem causar poluição de qualquer natureza em níveis que resultem ou venham a gerar danos à saúde humana, ou ainda, que provoquem a morte de animais ou a destruição significativa da flora, estará sujeito a pena de reclusão de um a cinco anos (art. 54 da Lei de Crimes Ambientais n. 9.605/1998).
} 


\section{PRÁTICAS SUSTENTÁVEIS PARA O DESEVOLVIMENTO SOCIOECONÔMICO}

O delineamento de programas de compliance, como, igualmente, a definição das variáveis cuja mensuração em concreto indicam o alcance da responsabilidade das empresas no momento ambientalmente delicado do pós-consumo do lixo eletrônico, são temas que exigem prévias considerações relativamente aos parâmetros de sustentabilidade, sem a qual, não há como se falar em desenvolvimento, e relativamente às prováveis ameaças ulteriores comprometedoras do sucesso de qualquer prática de compliance. $\mathrm{O}$ despreparo técnico, o açodamento, o desdém e até mesmo a deliberada intenção de comprometer os estudos preliminares asseguradores da futura sustentabilidade, mediante desprezo aos prováveis riscos, enfim, são fatores que merecem respeito prévio, sem cuja superação, qualquer programa de compliance teria sido inútil. Este é o desafio que se pretende enfrentar no presente tópico.

O desenvolvimento sustentável é uma meta global a ser atingida conforme a Agenda 2030 da Organização das Nações Unidas. O que se verifica é o alcance do desenvolvimento pela expansão econômica, pelo desenvolvimento humano e pela proteção e preservação ambiental. Tais providências são essenciais para a manutenção da humanidade e da saúde do planeta.

A sustentabilidade pode ser analisada como um fenômeno ideológico, jurídico, político e econômico, de caráter multidisciplinar (BLANCHET; COSTA JUNIOR, 2018), pois envolve aspectos diversos, que são objeto de estudo por outras áreas como, em especial, a física, a química e a engenharia, sem o que, não seria possível a efetivação de propostas realmente sustentáveis. Tais estudos validam a necessidade do uso de tecnologias verdes para a substituição de energias não renováveis que agridem o meio ambiente, medidas que devem estar associadas ao correto descarte do lixo para ulterior reaproveitamento através da logística reversa.

O desenvolvimento de estudos prévios de viabilidade de qualquer empreendimento ou prática empresarial sob os enfoques garantidores da sustentabilidade e eliminadores dos riscos, é o cuidado inicial inafastável e idôneo para identificação dos pontos básicos do conteúdo de qualquer programa de compliance. Sendo esses os pontos que darão segurança à definição das diretrizes de cada programa de compliance, pode-se concluir que é o descumprimento deles que determinará a amplitude da responsabilização em cada situação concreta. 
Partindo dessa premissa, a proposta de desenvolvimento sustentável objetiva o desenvolvimento social, a erradicação da pobreza, da fome e miséria, na implementação de ferramentas para o exercício da cidadania. Tais propostas permitem o acesso aos direitos fundamentais sociais relativos ao emprego, educação, moradia, segurança, saúde, previdência social, dentre outros, capazes de promover a dignidade e o bem-estar da população.

Quanto ao seu aspecto econômico, deve-se potencializar a democratização dos meios de acesso aos bens, respeitando a diversidade regional, cultural, sobretudo no que concerne aos recursos naturais, por serem essenciais para a manutenção das espécies e para a sobrevivência digna das comunidades tradicionais ribeirinhas, quilombolas e indígenas. Logo, as empresas possuem a Responsabilidade Social em face das comunidades onde atuam, de tal forma, que a atividade empresarial não pode orientar-se apenas pela procura do lucro, mas sim buscá-lo dentro dos parâmetros da ética, eficiência, racionalidade de recursos, planejamento e controle dos efeitos adversos (riscos ambientais).

A preocupação com o planeta, a seu turno, vai além daquela pertinente à responsabilidade dos Estados soberanos pelo controle e fiscalização das normas de proteção ambiental, pois a organização civil e as empresas devem assumir obrigações quanto ao consumo e gestão sustentável dos recursos naturais (DOMINGOS; VEIGA, 2017).

O desenvolvimento sustentável é um desafio para as nações, aqui consideradas em sua complexidade, abrangendo todos os seus setores, assim na área pública como no âmbito privado. É necessária a adoção de um conjunto de medidas racionais para a preservação e tutela das espécies, como a redução de fatores poluentes que implicam a alteração climática e o comprometimento da qualidade do ar, garantindo que as presentes e futuras gerações possam desfrutar de um meio ambiente saudável.

$\mathrm{O}$ conceito global de sustentabilidade está relacionado à solidariedade de todos para a efetiva preservação dos recursos naturais, especialmente água, solo, biodiversidade, vitais para a sobrevivência da humanidade.

As normas pertinentes ao direito ao meio ambiente, elevadas à categoria de normas formalmente constitucionais, estão situadas no capítulo da ordem social. Trata-se de direito fundamental, considerado Direito de Terceira Dimensão, influenciado por valores de solidariedade para fins de harmonização na relação entre o ser humano e seu meio, com especial destaque à fauna e à flora, assim como todos os fatores naturais que possibilitam sustentabilidade de ambas. 
Extrai-se do art. 225 da Constituição da República, importante norma, assegurando a todos o direito ao meio ambiente ecologicamente equilibrado, essencial à viabilização e manutenção da dignidade humana, cuja defesa se impõe ao Poder Público e a toda coletividade.

Os princípios definidos pela Constituição orientadores da Administração Pública e não apenas os expressos no art. 37, são essenciais para o equilíbrio entre a racionalidade da exploração econômica e o impacto sobre o meio ambiente, cabendo ao Estado, no exercício do poder de polícia e em sua função de fomento, levar a efeito o constante monitoramento, e conceder incentivos à pesquisa e produção de tecnologias verdes.

No intuito de superar a crise climática com metas de médio e longo prazo, é preciso adotar políticas no plano econômico, cultural, social e ambiental (COLOMBO; FREITAS, 2016), através de práticas globais de respeito aos povos e cooperação com os demais atores para a prevenção de danos ambientais.

Além da prática preventiva do compliance, é necessário tornar a legislação ambiental efetiva, principalmente para prevenir o favorecimento de interesses pessoais na concessão de licenças, inclusive para a exploração de minerais e construção de empreendimentos em áreas de preservação e terras indígenas.

\subsection{O paradigma entre o desenvolvimento e a sociologia do risco}

O desenvolvimento pautado apenas por critérios econômicos com o lucro como fator principal, tem se revelado insuficiente e impróprio isoladamente, para o atendimento da Agenda 2030 de Sustentabilidade Global promovida pela Organização das Nações Unidas. ${ }^{4}$ Essa crítica se deve às consequências climáticas que afetam as comunidades em que as empresas atuam, motivo pelo qual, há necessidade de mediação de conflitos entre a expansão econômica e preservação de recursos naturais.

De fato, os riscos econômicos e ambientais são sentidos de forma global; as catástrofes cujos efeitos antes eram confinados a áreas geográficas específicas passam a interferir na saúde da população local e no bem-estar global. A título de exemplo, o descongelamento das geleiras é, sob um enfoque, motivado pelo aquecimento da terra e, sob outro, contribui para

4 O problema do uso irresponsável dos recursos naturais atrelado a contaminação da atmosfera tem atraído a atenção da Organização das Nações Unidas (ONU) para o controle de poluentes e o correto descarte do lixo. Ao todo são 17 objetivos globais para o desenvolvimento sustentável, dentre eles é possível identificar a redução das desigualdades, além de medidas de bem-estar social que permitem uma vida mais justa, tornando possível o reequilíbrio do ecossistema, cf. ONU (2019). 
seu agravamento, resultando sempre em desastres ambientais.

Quanto aos problemas climáticos gerados no Brasil, verifica-se que o crescente desmatamento da Amazônia ao longo dos séculos, tem refletido no desequilíbrio das chuvas no cenário nacional.

No ano de 2018, os Estados do Mato Grosso, Roraima e Tocantins somaram cerca de $55 \%$ dos focos de incêndios identificados no País, fato explicado pelo clima quente e seco dessas regiões, mas também pelo reiterado desmatamento e degradação ambiental para a expansão de madeireiras e empreiteiras, tornando mais difícil a recomposição vegetal da floresta (RORAIMA..., 2018).

Sobressai nessa análise, o estudo realizado por um grupo de pesquisadores de Universidades Americanas, que identificaram o impacto do desatamento Amazônico nas chuvas de Rondônia. Assim, na medida em que se remove a vegetação, altera-se o atrito que antes era realizado pelas árvores na circulação da atmosfera e isso reduz drasticamente as chuvas nas regiões onde ocorreu o desflorestamento (KHANNA et al., 2017).

Nessa lógica, a chuva que era concentrada no centro, acaba se deslocando mais para um lado, alterando a quantidade e a localidade da precipitação (deposição de água para superfície da terra) e como consequência, há pontos da Floresta com menor quantidade de chuva, por causa da redução de rugosidade da superfície desmatada (CHAMBERS; ARTAXO, 2017). Veja-se que a assim provocada irregularidade de chuvas tornou mais intensas as consequências do fenômeno El Niño (NOBRE et al., 2016), dado o aquecimento anormal das águas do Pacífico Tropical. Além disso, sem árvores, a Floresta Amazônica não é capaz de absorver o gás carbônico responsável pelo efeito estufa, tornando os efeitos climáticos mais extremos em todo o globo.

Insta salientar, que o desmatamento não é o único fator responsável pelas catástrofes naturais, a queima de combustíveis fósseis é considerada a maior causa das mudanças climáticas. Apesar de serem considerados, o petróleo, o gás natural e o carvão, importantes para o setor da energia em atividades industriais e para o funcionamento de veículos, os recursos são escassos e altamente poluentes. Analisada com a objetividade que o assunto exige, pode-se afirmar que o ser humano foi atraído irracionalmente pelo suposto desenvolvimento, que os combustíveis fósseis propiciavam e defronta-se hoje com um impasse que, se não superado, somente agravará a funesta insustentabilidade desse processo.

Houvesse no passado, no plano da conscientização, a preocupação 
que hoje é inquestionável pela sustentabilidade e, no plano da ação, a adoção de práticas de compliance, ter-se-ia percebido a tempo que o uso desenfreado de combustíveis fósseis era um engodo e não um caminho para o desenvolvimento. Outra causa que se reflete na qualidade da atmosfera, se dá com a ausência de política eficaz para o reaproveitamento do lixo. A queima ilícita de resíduos sólidos urbanos emite dióxido de carbono $\left(\mathrm{CO}_{2}\right)$, um dos principais gases relacionados ao efeito estufa (MAIELLO; BRITTO; VALLE, 2018).

Beck e Beck-Gernsheim (2008) ressaltam a importância na contenção de riscos para antecipação de catástrofes. Essa nova consciência global cria espaços para modelos alternativos de produção e uma interpretação moral e política capaz de absorver uma cultura internacional de responsabilidade ambiental.

Assim, as práticas aparentemente inofensivas pela busca do lucro como único motor do desenvolvimento, as quais, aos poucos foram se tornando usuais, se sobrepõem às necessidades coletivas. O problema requer uma reflexão entre Estado, empresas e sociedade para que sejam implementadas práticas menos danosas aos recursos naturais.

As economias em desenvolvimento passam por problemas de cunho estrutural, que envolvem altos índices de desemprego, precarização do trabalho, além do aumento da inflação e desrespeito ao meio ambiente. Esses obstáculos, despertam o interesse coletivo em projetos de desenvolvimento sustentável e de ressignificação econômica e política. Por conseguinte, é necessário que o setor econômico disponha de autonomia para implementação de políticas internas e mobilidade comercial com outros países, a fim de trazer inovações sustentáveis e competitividade para empresas, permitindo a redução das desigualdades regionais (CARDOSO JR, 2011).

Vale dizer, que o desenvolvimento regional sustentável ${ }^{5}$ pode ser traduzido pelas políticas públicas de saneamento básico, acesso à água potável, incentivo às cooperativas, como por exemplo as que realizam trabalho na coleta e reciclagem de resíduos sólidos urbanos.

Com efeito, o ponto tido como plausível para o desenvolvimento sustentável, está relacionado com a atuação Estatal e empresarial em

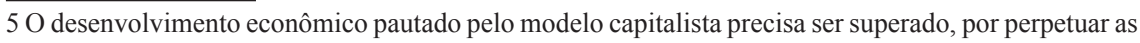
desigualdades sociais, favelização, desemprego e a destruição da biodiversidade. Um desenvolvimento regional regido pela sustentabilidade somente é possível com ações governamentais integradas, no âmbito federal, estadual e municipal, oportunizando a participação da comunidade local nos processos decisórios junto aos Conselhos Municipais e Estaduais de Fiscalização, em consonância com os objetivos estabelecidos coletivamente (ALVES; KNOREK, 2010, p. 13-23). 
consonância com o ordenamento jurídico, possibilitando que as estratégias de desenvolvimento façam parte dos objetivos das organizações, conforme os parâmetros normativos e as determinações dos órgãos técnicos de proteção ambiental. O Estado tem por escopo a formulação de políticas públicas de caráter preventivo sobre os biomas, servindo como guideline para que as empresas elaborem os seus programas de compliance.

Amartya Sen (1999) acertadamente alerta que o crescimento econômico sem respeito à humanidade leva à pobreza das nações. Para o autor, a economia deve estar alinhada às práticas éticas para a construção da liberdade e expansão das capacidades individuais, através da educação, oportunidades de trabalho, acesso à saúde, estar bem nutrido, dentre outros direitos sociais fundamentais.

Dessa forma, as corporações têm de realizar a avaliação social dos seus projetos, assim como os impactos de seus produtos no meio ambiente. O desenvolvimento econômico não pode ser alcançado a qualquer custo, as consequências ambientais geram desequilíbrios sociais que são pagos por todos.

Apesar da implementação da Política Nacional de Resíduos Sólido - PNRS (Lei n. 12.305/10), o Brasil atua na contramão, em virtude do reaproveitamento inferior à média europeia (30\%), conforme os indicadores obtidos pela European Environment Agency (EEA, 2016).

Estima-se que mais de 160 milhões de toneladas de resíduos sólidos são jogados no meio ambiente por dia, contudo, apenas 13\% do lixo total é aproveitado na reciclagem (IPEA, 2017). A geração de lixo no Brasil aumentou quase 30\% nos anos entre 2003 a 2014, em razão do consumo exacerbado (BRASIL, 2014). Além disso, atualmente, mais de 1,6 mil cidades ainda não contam com medidas de separação de resíduos, tornando impossível a aplicação da logística reversa (MELLO, 2018). Atualmente, com a proibição de envio de resíduos para a China, a Tailândia passa a ser considerada o novo destino do lixo eletrônico mundial, graças à fraca repressão das autoridades locais e à ausência de leis sobre gerenciamento de resíduos (LEE, 2018).

A África, o Sudeste Asiático e a América Latina, ressalvadas as políticas já adotadas isoladamente por algumas regiões, possuem déficit na coleta e reaproveitamento de lixo, nessas localidades há ausência de uma política efetiva de saneamento básico, que contribui para a contaminação do lençol freático, com o risco de doenças graves (problemas cardíacos, câncer e, possivelmente, alterações no DNA humano). 
O tratamento dos resíduos eletrônicos é um problema de ordem global negligenciado pelas principais potências industriais, que não estão preocupadas em desenvolver um projeto de pesquisa e tecnologia para a logística reversa desse material. As multinacionais mal-intencionadas, se aproveitam de fábricas ilegais, em condições de trabalho insalubres, geralmente localizadas em países subdesenvolvidos para depositar o seu lixo eletrônico, disfarçado de equipamento elétrico de segunda mão. Devido às falhas constantes de fiscalização e ausência de maquinário especializado para o reaproveitamento dos componentes, o resíduo eletrônico acaba sendo despejado de forma inadequada em aterros sanitários.

No Brasil, o descarte incorreto do lixo eletrônico é responsável por contaminar o meio ambiente. Também se verifica o déficit de pontos destinados à coleta seletiva, além de que a população ainda não se conscientizou da importância da logística reversa e seu aspecto econômico (CERATTI, 2017).

A Política Nacional de Resíduos Sólidos (PNRS) visa eliminar o descarte incorreto do lixo eletrônico no meio ambiente ${ }^{6}$. Para que isso seja possível, os gestores públicos devem incentivar projetos que permitam a inclusão social, capacitação e oportunidades de emprego no mercado formal para as cooperativas de catadores, juntamente com empresas especializadas em e-waste (lixo eletrônico).

Com o avanço da tecnologia, é possível extrair metais preciosos de resíduos que estão presentes em placas de computadores, celulares e demais eletrônicos. O cobre, prata e ouro, podem ser vendidos como matéria-prima para a fabricação de novos componentes eletrônicos ou para a indústria de joias.

Não obstante, a logística reversa nacional ainda possui um alto custo quando comparada com países Europeus, tornando o mercado pouco atrativo para as empresas. É preciso que os agentes políticos vejam o grande potencial da reciclagem, que vai além da aplicação meramente formal da PNRS, mas que afete a consciência coletiva desde o fabricante, comerciante, consumidor, distribuidoras e cooperativas de catadores, para que no futuro seja possível a mineração de componentes eletrônicos de forma limpa e sustentável.

6 Dentre as medidas necessárias para a real logística reversa, os fornecedores, comerciantes, fabricantes e importadores podem: a) implantar procedimentos de compra de produtos ou embalagem usados; b) estabelecer postos de entrega de resíduos reutilizáveis e recicláveis (alguns supermercados têm adotado máquinas para o recolhimento de pinhas e baterias); b) atuar em conjunto com cooperativas ou outras formas de associação de catadores, responsáveis pela coleta de materiais reutilizáveis e recicláveis, nos casos previstos do art. $\S 1^{\text {a }}$, do art. 33 da PNRS. 
Visando mudar o crescente número de lixões e aterros sanitários, Costa Rica, México e Brasil ampliaram seus investimentos em empresas que atuam na reciclagem de resíduos sólidos urbanos, assegurando o padrão internacional $\mathrm{R} 2^{7}$, que tem por finalidade dar maior segurança no manejo de componentes eletrônicos para os trabalhadores e meio ambiente.

Acerca deste tema, o Estado do Paraná em conjunto com a Secretaria do Meio Ambiente e recursos hídricos, desenvolveu o grupo R20 (Decreto Estadual n. 8657/2013), composto por 20 regiões municipais definidas pelo Plano Estadual de Regionalização da Gestão Integrada de Resíduos Sólidos, a fim de padronizar o nível de excelência internacional na coleta e descarte dos resíduos sólidos na região.

Nas conferências ambientais, os colaboradores Municipais e engenheiros técnicos do meio ambiente apresentam propostas para a desativação de lixões, bem como empresas com enfoque na área de reciclagem possuem espaço para a elaboração de projetos de inovação, possibilitando o manejo inteligente dos resíduos e políticas públicas no pós-consumo.

A cooperação entre órgãos técnicos de proteção ambiental, Secretarias Municipais do Meio Ambiente e empresas, torna possível o fomento e pesquisa para a logística reversa, efetivando a adequação do Plano Nacional de Resíduos Sólidos, sobretudo quanto ao destino adequado do lixo eletrônico.

As empresas que desenvolvem produtos eletrônicos passam a utilizar os mecanismos de compliance para a adequação das normas ambientais, entendendo que o custo adicional da consultoria especializada se torna necessário para evitar os efeitos indesejáveis no ambiente, além de maiores problemas com os órgãos técnicos de proteção ambiental e possível cassação de licença de operação.

\section{PROGRAMAS DE COMPLIANCE PARA A TUTELA AMBIENTAL}

Compliance, é um substantivo derivado do verbo to comply que, em Inglês, significa agir em conformidade com o ordenamento jurídico

\footnotetext{
7 O documento R2:2013 Standard é responsável por estabelecer práticas de reciclagem de componentes eletrônicos no cenário global através do Certification Body (Órgão de Certificação), este garante que os equipamentos eletrônicos sejam gerenciados de forma responsável, protegendo a segurança e saúde dos funcionários e do meio ambiente. Ademais, o Padrão R2:2013 ressalta o valor do produto para os stakeholders (clientes, funcionários, comunidade e o público), além da exigência de conformidade com as leis e regulamentações de todos os países envolvidos na importação, trânsito e exportação (SERI, 2014).
} 
vigente, sendo compatível com as políticas e diretrizes da organização e normas de amplitude internacional para a proteção da dignidade humana.

Apesar do termo ser originalmente do sistema financeiro norte-americano, o que se observa é a importação dos programas de compliance ao ordenamento jurídico brasileiro.

O Superior Tribunal Federal utilizou referido instituto para o julgamento da Ação Penal 470 (Mensalão). O STF compreendeu que os códigos de condutas previstos nos programas de compliance possibilitam a implementação de ações em consonância com a Lei, resoluções e atos proferidos pelo Banco Central (BRASIL, 2012), no sentido de promover a transparência e ética, com a obrigatoriedade de prestar contas aos órgãos de controle e persecução criminal.

A Lei Anticorrupção n. 12.846/2013 permitiu a responsabilização da pessoa jurídica nas três esferas (administrativa, civil e criminal) pela prática de atos em prejuízo da Administração Pública, nacional ou estrangeira, sendo comparada com a Federal Sentencing Guidelines Manual, dos Estados Unidos. ${ }^{8}$

A responsabilidade judicial das empresas segue o rito previsto na Lei da Ação Civil Pública n. 7.347/1985 e no art. 21 da Lei 12.846/2013. O Ministério Público, por sua vez, irá investigar a extensão do dano e o nexo causal entre a atividade desenvolvida pela organização (GUARAGNI; CHIAMULERA, 2015).

Os responsáveis pela condução de programas de compliance devem atuar em cooperação com os órgãos de persecução criminal, para a mitigação da corrupção e de possíveis danos ambientais, conforme apontado na Lei de Anticorrupção Empresarial n. 12.846/2013.

A principal finalidade dos programas de compliance é evitar a prática de condutas ilícitas dentro da organização. A atuação do compliance officer ${ }^{9}$ deve ser em tempo hábil, antes da incidência do Direito Penal, evitando que haja conduta que cause dano ou ofereça perigo ao bem-jurídico tutelado pelo Estado (SAAVEDRA, 2011).

8 Para maiores detalhes sobre os programas de compliance previstos na Federal Sentencing Guidelines Manual, cf. Saris (2016, p. 525 e ss).

9 O compliance officer é responsável pelo controle interno, gestão de riscos e o monitoramento dos contratos com base nas diretrizes legais. Dessa forma, realiza a função de orientação e coordenação, haja vista que não possui o dever de garante, tal como ocorre com a alta administração, mas sim de implementar um programa de governança e integridade corporativa que alcance todos os membros da corporação. Portanto, quando verificados atos ilícitos ou suspeitos (dentro da sua esfera de proteção), o compliance officer possui o dever de comunicar diretamente a alta administração e os canais de denúncia da empresa, sob pena de imputação de responsabilidade pelos órgãos de persecução criminal (GÓMEZ-JARA DÍEZ, 2015). 
Os programas de compliance tiveram início nos Estados Unidos com a finalidade de obstar fraudes associadas à queda da bolsa de valores nos anos de 1930. Porém, foi somente na década de 50, com a regulação antitruste e o direcionamento do governo para o combate à corrupção, que o compliance foi integrado aos sistemas jurídicos.

A Lei Sarbanes-Oxley (SOX, 2002) é vista como um divisor de águas para a governança corporativa, pois foi responsável por promover a transparência dos negócios ${ }^{10}$, além de coibir fraudes contábeis das companhias norte-americanas e demais empresas que comercializam seus títulos no mercado financeiro, nas ações da Securities and Exchange Comission (VERÍSSIMO, 2017).

A Lei Sox 2002 exige, dos executivos financeiros, mudanças efetivas e sustentáveis que ampliem a transparência das transações, caso contrário pode haver responsabilização dos executivos pela atuação não recomendável ou criminosa.

Busca-se, assim, com a governança coorporativa, preservar a conformidade legal gerada pelos programas de compliance, a devida prestação de contas (accountability) por meio dos portais de transparência, a implementação da ética e do senso de justiça, que afetam os shareholders (acionistas) e stakeholders (público estratégico, sociedade, empregados e demais indivíduos que podem ser impactados pela empresa).

Atualmente, os programas de compliance foram expandidos para diversos setores, não sendo mais restritos aos programas de combate à corrupção no ramo empresarial. O compliance se tornou sinônimo de auto regulação da empresa para o devido cumprimento de normas e condutas éticas. O compliance é utilizado no ramo trabalhista, ambiental, tributário, comercial e hospitalar. Assim, quando efetivamente implementado, pode contribuir para a expansão da atividade empresarial e a redução de riscos.

Apesar da aplicação do compliance significar alto custo para a empresa, deve ser considerado como uma medida eficiente na contenção de riscos normativos e ambientais, considerando que o simples envolvimento da empresa em processo de responsabilização ambiental leva à desvalorização da marca e ao desincentivo de investidores para com os negócios da organização.

É importante esclarecer que os programas de compliance atingem todos os envolvidos da empresa, desde a portaria, empregados, fornecedores e terceirizados aos executivos dirigentes da alta administração.

10 Sobre o assunto, cf. SOX (2002). 
Dessarte, ainda que ocorra delegação do dever de vigilância ao compliance officer, isto não afasta a responsabilização dos dirigentes, posto que o dever de vigilância da alta administração jamais se extingue, a transferência de obrigação é sempre parcial.

\subsection{A responsabilidade da empresa no dano ambiental}

A responsabilidade é um dos temas importantes para a mitigação de danos em face do meio ambiente, pois busca alcançar a reparação e coibir a prática de ilícitos. No Brasil, antes mesmo do Código Civil de 1916, o Decreto Lei n. 2.681 de sete de dezembro de 1912 já previa a responsabilidade civil objetiva aplicável ao transporte ferroviário. Em seu art. 17, estabeleceu a responsabilidade das companhias de estradas de ferro pela morte, lesão corpórea ou ferimento sofridos pelos passageiros nas suas linhas férreas (ANTUNES, 2015).

Mais tarde, o Código Civil de 1916 compôs a responsabilidade civil derivada da culpa, dessa forma, o indivíduo era obrigado a reparar o dano, quando por ação ou omissão voluntária, negligência ou imprudência, violasse direito ou causasse prejuízo a outrem, com base no art. 159 (BRASIL, 1916).

Por conseguinte, o Código Civil de 2002 inova em seu art. 927 ao tratar especificamente da responsabilidade objetiva, independente de culpa, nos casos especificados em lei, ou quando a atividade normalmente desenvolvida pelo autor do dano implicar, por sua natureza o risco de outrem (BRASIL, 2002).

Dessa forma, a responsabilidade objetiva é pautada pela noção de risco social que está implícito em certas atividades desenvolvidas ${ }^{11}$, como na indústria, transporte, usinas nucleares, produção de substância nocivas à saúde e ao meio ambiente, dentre outros. ${ }^{12}$ Assim, não faz sentido transferir para a sociedade o ônus de suportar os prejuízos causados pelo poluidor, dada a sua vulnerabilidade, como parte mais frágil da relação, bem como a dificuldade para o acesso à justiça, além do alto custo dos laudos técnicos periciais e a mora processual.

11 A base da responsabilidade do Código de Defesa do Consumidor - CDC (Lei n. 8.078/90), também advém do risco da atividade, motivo pelo qual prescinde da culpa do fabricante e fornecedor (art. 12 e 14).

12 A teoria do risco integral não admite as excludentes de responsabilidade civil, como a culpa exclusiva da vítima, fato de terceiros e caso fortuito e força maior, portanto, o risco social da atividade desenvolvida pela empresa sobre o meio ambiente e sociedade, é visto como suficiente para imputar responsabilidade pelos danos causados, independentemente de culpa (BEDRAN; MAYER, 2013, p. 45-88). 
No que concerne ao dever de reparação ambiental, a Constituição ampliou sua preocupação com o meio ambiente, ao estatuir no art. $225 \S$ 3 , a aplicação de sanções penais e administrativas, independentemente da obrigação de reparar os danos ambientais.

A responsabilidade objetiva também é estabelecida nas seguintes leis: a) Política Nacional do Meio Ambiente - PNMA (Lei n. 6.938/81), que foi uma das primeiras a tratar da responsabilidade objetiva para a proteção do meio ambiente, impondo ao poluidor e ao predador, a obrigação de recuperar e indenizar os danos causados, com base no art. 4, inciso VII; b) Lei de Biossegurança (Lei n. 11.105/2005); c) Lei que institui a Política Nacional de Resíduos Sólidos (Lei n. 12.305/2010); d) Novo Código Florestal (Lei n. 5.869/1973).

Já a Lei de Crimes Ambientais (Lei 9.605/98) estabelece a responsabilização penal da empresa, bem como a responsabilidade solidaria entre a empresa e seus integrantes, que pode tornar possível a desconsideração da personalidade jurídica. ${ }^{13}$

O poluidor pode ser tanto pessoa física como jurídica, posto que a responsabilidade civil por danos ambientais é objetiva ${ }^{14}$. Portanto, aquele que causar dano ou risco de dano ambiental será obrigado a indenizar ou reparar os danos patrimoniais e extrapatrimoniais (morais) que forem causados em face de terceiros e do meio ambiente. Não é necessário provar a culpa, basta a existência do dano e do nexo causal, conforme o art. 225, parágrafo $3^{\circ}$, da Constituição.

Em tese, o dano extrapatrimonial coletivo ocorre quando atinge a esfera moral da sociedade, visto que o direito fundamental ao meio ambiente é de titularidade difusa. A sua ofensa consiste na diminuição da qualidade de vida, desiquilíbrio ecológico ou ainda, quando o poluidor lesiona determinado espaço, bioma, gerando danos físicos, psicológicos ou risco à saúde dos indivíduos.

O pagamento da indenização é fixado com base na gravidade do dano e nas circunstâncias específicas do infrator, portanto, demostrada a sua ilegalidade, se faz necessária a condenação do poluidor, a fim de

$13 \mathrm{O}$ art. 225, parágrafo terceiro prevê a responsabilização administrativa civil e penal, das pessoas jurídicas no caso em que a infração seja cometida por decisão de seu representante legal ou contratual, ou de seu órgão colegiado, no interesse ou benefício de sua entidade.

14 O Superior Tribunal de Justiça (STJ) admite a Teoria do Risco Integral ao poluidor aduzindo que a reponsabilidade civil por dano ambiental é objetiva e solidária, afeta todos aqueles que participaram da atividade danosa ao meio ambiente ou que obtiveram proveito, com fulcro no art. 14, parágrafo primeiro da Lei n. 6.938/81, combinado com o art. 942 do Código Civil, cf. Wedy (2018). 
compensar os danos ambientais sofridos pela coletividade. ${ }^{15}$ Salienta-se que o pagamento realizado pelo poluidor não lhe atribui direito a poluir, pois o que se pretende é a prevenção do dano e o dever de reparação (MACHADO, 2012).

De acordo com Cappelli (2004), a prática de condutas criminosas pode ocasionar efeitos nocivos ao meio ambiente, em certos casos, de impossível reversão, como no desastre ocorrido na barragem de fundão, na cidade Mariana - Minas Gerais, no ano de 2015. Ainda que o compliance officer tenha comunicado os dirigentes responsáveis sobre a fragilidade da barragem, mesmo assim, não foram tomadas as devidas medidas pela mineradora para afastar o risco de quebra da barragem e, por conseguinte, a contaminação do Rio Doce.

O rompimento da barragem na cidade de Mariana ocasionou a morte de 19 pessoas, além do dano ambiental e econômico sofridos pela comunidade local (PARREIRAS, 2018). A responsabilidade da empresa é objetiva (dispensa o elemento culpa), consiste no dever de utilizar a racionalidade com adoção de medidas mais sustentáveis, que implicam a revisão periódica e o uso de tecnologias para afastar o risco da sua atividade sobre o meio ambiente.

Oportuno lembrar que, em janeiro de 2019, ocorreu mais uma tragédia envolvendo a empresa Vale S.A. e a população de Minas Gerais, com o rompimento da barragem 01, na cidade de Brumadinho (WENTZEL, 2019).

Apesar do laudo técnico assinalar que o risco de rompimento era de grau leve (RODRIGUES, 2019), era perceptível que o refeitório, a pousada, residências e o setor administrativo foram construídos em local inadequado, nas proximidades da barragem, o que dificultaria a execução de um plano de emergência e de evacuação diante da ocorrência de um evento desastroso.

Infere-se, portanto, o que diferencia a tragédia gerada pela exploração de minérios nas cidades de Mariana e Brumadinho, é que a primeira foi reconhecida como maior desastre ambiental do país. Por outro lado, a segunda é vista como ecocídio (um crime contra a humanidade), em razão do soterramento de aproximadamente 310 pessoas, sendo 248 óbitos identificados e 22 pessoas que ainda se encontram desaparecidas ou não identificadas, além da destruição da vegetação e da contaminação do rio

15 De forma elucidativa, veja-se a Ação Civil Pública Ambiental para a condenação por dano ambiental coletivo em razão de desmatamento e a obrigação do poluidor em reparar a área degradada (TJ-MG, 2018, p. 1). 
Paraopeba, um dos afluentes do São Francisco.

Estendendo essa percepção, fica visível a fragilidade técnica dos órgãos ambientais e da Administração Pública para implementar efetivo controle e fiscalização das empresas que atuam na exploração ambiental.

O que se espera dos agentes econômicos, é a sua atuação em consonância com o ordenamento jurídico e as normas de proteção do meio ambiente, por iniciativa própria, para o real cumprimento da função social da empresa, principalmente no que tange à racionalidade dos recursos naturais e à saúde e bem-estar da população que está em condição social e biológica mais frágil.

As empresas, portanto, precisam estar em conformidade (compliance) com as normas ambientais, adquirindo tecnologia necessária para a separação e o melhor reaproveitamento dos bens de consumo em outros processos produtivos, destinados às indústrias de logística reversa. Já o Poder Público deve fiscalizar as empresas, mesmo durante o prazo de validade da licença de operação (equivalente a quatro a seis anos), como forma de prevenção de possíveis danos contra o meio ambiente.

\subsection{Logística reversa dos produtos eletrônicos}

A tutela jurídica para a proteção ambiental compreende a responsabilidade compartilhada entre a empresa, fabricantes, importadores, distribuidores e comerciantes quanto ao destino dos produtos. A Política Nacional de Resíduos Sólidos (PNRS Lei n. 12.305/10) estabelece que as empresas devem criar inciativas para o recolhimento dos seus produtos no pós-consumo, em observância ao princípio do poluidor pagador. ${ }^{16}$

Os consumidores e gestores governamentais também assumem responsabilidade quanto ao destino final dos produtos. $\mathrm{O}$ consumidor deve observar os pontos de coleta para o correto descarte do resíduo, minimizando o volume do lixo eletrônico no ecossistema.

Leite $(2009$, p. 32) entende que a prática da logística reversa no pós-consumo é estabelecida através do fluxo reverso de parte dos produtos

$16 \mathrm{O}$ princípio do poluidor pagador parte do pressuposto que os recursos ambientais são escassos e a sua exploração para fins econômicos, seja na produção ou consumo, acarreta degradação ambiental. Em consonância disso, o Estado interfere no mercado para eliminar os custos sobre a coletividade e direcionar exclusivamente aos produtores e consumidores. Para Antunes (2015), a aplicação do referido princípio se baseia da atuação preventiva e na identificação clara do custo ambiental para assim, poder estabelecer os parâmetros de cuidado sobre a atividade empregada. Veja-se que, o consumidor possui a sua responsabilidade cessada com a disponibilização adequada do resíduo para a coleta, ou ainda, com a devolução, em conformidade com o art. 33 e art. 28 da PNRS. 
ou materiais que foram descartados após o uso, no sentido de que esses materiais ou componentes podem retornar para o ciclo produtivo por meio da reciclagem ou reuso. Racionalmente, os canais de pós-venda permitem a reutilização do produto por um novo consumidor, exemplo disso, é o comércio de carros usados, que possibilita a mudança de proprietário até o término da utilidade do veículo.

Dessa forma, as empresas estabelecem o compromisso de oferecer pontos de descarte e coleta no pós-venda, o que possibilita o destino adequado para aqueles produtos que antigamente eram considerados lixo, despejados de forma inadequada em aterros ou lixões.

A logística reversa terá impacto substancial no Brasil somente se houver políticas públicas de educação ambiental na separação dos resíduos sólidos pelos consumidores, além de estabelecer práticas inteligentes de reutilização dos produtos. A falta de recursos financeiros e o descaso do Estado para com os órgãos de fomento à pesquisa e inovação tecnológica no pós-consumo, fazem com que se tenha baixo índice de devolução e reciclagem de produtos eletrônicos e, consequentemente, os componentes tóxicos desses materiais acabam sendo depositados em lixões ou aterros sanitários, contaminado o solo e leitos dos rios.

Vale ressaltar que as empresas possuem responsabilidade na adoção de estratégias que favoreçam o meio ambiente, posto que parte significativa do lixo tecnológico é utilizada pelas mesmas, para a execução de seus serviços e produtos.

O mais importante, é que a política de logística reversa seja incrementada desde a concepção do produto, com base em todas as etapas do seu ciclo de vida. O design ecológico deve possibilitar a desmontagem e substituição de peças, com a possibilidade de upgrade de software (PAPANEK, 2009).

Não há como negar, que a responsabilidade compartilhada impõe a todos os participantes do ciclo de vida do produto, o dever de minimizar o volume de resíduos, rejeitos e lixo eletrônico no meio ambiente, empregando todos os meios possíveis para a correta destinação dos resíduos, sobejados após o uso e descarte do produto pelo consumidor (GUERRA, 2012).

Nesse contexto, a responsabilidade Ambiental opera-se de forma compartilhada, individualizada e encadeada, com fulcro no art. 33 da Política Nacional de Resíduos Sólidos - PNRS (Lei n. 12.305/2010). Os fabricantes, importadores, distribuidores e comerciantes devem realizar a logística reversa, de forma independente do serviço público de limpeza urbana e manejo dos resíduos sólidos. ${ }^{17}$

17 A responsabilidade se estende ao cidadão que possui o dever de descartar o produto em local adequado, possibilitando a sua reciclagem (art. 33, § 4) e, o Estado de implementar a Política de 
O referido dispositivo prevê a implementação da logística reversa de modo imediato (art. 33, I a IV) ou progressivo com base no caso concreto (art. 56 cumulado com art. 33, V e VI). A Lei de Crimes Ambientais n. 9.605/98 estabelece a responsabilização penal da empresa, bem como a responsabilidade solidária entre a empresa e seus integrantes, implicando a desconsideração da personalidade jurídica. ${ }^{18}$

Nestecaso,épossível queo Poder Judiciário ao aplicara responsabilidade no pós-consumo, determine a implementação progressiva dos sistemas de logísticas reversas em atenção à elaboração do cronograma. ${ }^{19}$

No parágrafo $3^{\circ}$ do artigo 33 (PNRS), a responsabilidade dos fornecedores consiste em tomar todas as medidas necessárias para assegurar a implementação e operacionalização do sistema de logística reversa.

Entretanto, o que se verifica é a ausência de adequação das empresas para o devido manejo do lixo eletrônico; assim, como países desenvolvidos, o brasileiro passa a descartar produtos em perfeitas condições de uso, em razão da "obsolescência psicológica" 20 para aquisição de um produto "melhor", com software atualizado, que não reflete um upgrade significativo no produto (SLADE, 2007).

Observa-se que os catadores, que antes trabalhavam com resíduos sólidos, passam a ter contato com substâncias tóxicas, em busca do cobre e ouro contido nos produtos eletrônicos. Considera-se que o contato direto do trabalhador com produtos nocivos pode ocasionar enfermidades neurológicas, respiratórias e alérgicas, além do risco de deformação do feto no período gestacional, devido à elevada toxicidade do chumbo e do mercúrio composto nas baterias de celulares e notebooks. ${ }^{21}$

Resíduos para a efetivação da logística reversam cujo objetivo é reaproveitar o ciclo produtivo, transformando o lixo em uma destinação final ambientalmente sustentável, servindo de instrumento econômico e social em razão do potencial lucrativo da atividade, com base no art. $3^{\circ}$, inciso XII, da Política Nacional de Resíduos Sólidos de 2010 (PNRS).

$18 \mathrm{O}$ art. 225, parágrafo terceiro prevê a responsabilização administrativa civil e penal, das pessoas jurídicas no caso em que a infração seja cometida por decisão de seu representante legal ou contratual, ou de seu órgão colegiado, no interesse ou benefício de sua entidade.

19 Art. 56. A logística reversa relativa aos produtos de que tratam os incisos V e VI do caput do art. 33 será implementada progressivamente segundo cronograma estabelecido em regulamento. Art. 33, incisos V-lâmpadas fluorescentes, de vapor de sódio e mercúrio e de luz mista; VI-produtos eletroeletrônicos e seus componentes.

20 A obsolescência psicológica é reconhecida como subjetiva, pois leva em conta as referências emocionais, status, moda e qualidade estética. Pode-se afirmar que a obsolescência psicológica vai de encontro com a insatisfação do consumidor pela ausência de atualização dos produtos eletrônicos (ECHEGARAY, 2015), principalmente na redução intencional da vida útil de tablets $e$ smartphones, que são excluídos de Security Updates, tornando-se lentos e vulneráveis aos ataques de hackers. Tal prática é institucionalizada pelos fabricantes, contudo, contraria as propostas globais de sustentabilidade, em razão de estimular a substituição do produto antes da sua quebra ou falha técnica.

21 Os riscos para saúde são agravados pelas condições socioeconômicas da população, ou seja, as 
As consequências sociais são inúmeras, o Brasil lidera o ranking de geração de lixo eletrônico na América Latina ${ }^{22}$. O Estado do Paraná é um dos principais produtores de lixo. Somente na cidade de Curitiba, são retirados cerca de 500 quilos de lixo eletrônico por ano através do apoio da Companhia de Tecnologia da Informação e Comunicação do Paraná - Celepar; a organização de catadores atua na coleta reciclável e possui certificação internacional de responsabilidade (CELEPAR, 2018). $\mathrm{O}$ volume de lixo recolhido poderia ser mais expressivo se houvesse um plano de consciência ecológica para as empresas e sociedade com apoio do governo, para o correto descarte desse material.

Ainda no Estado do Paraná, o Município de São José dos Pinais elaborou a Lei n. 2566 de maio de 2015 para implantação de eco pontos na cidade (CMSJP, 2015), reconhecendo como resíduos perigosos e especiais: a) lâmpadas fluorescentes; b) lixo eletrônico e de informática; c) óleo de fritura; d) bitucas de cigarro; e) isopor; f) baterias de celular; g) pilhas; h) reatores de luminárias; i) tintas e solventes; j) chapas de raio-X; k) banners e faixas de lonas; 1) baterias veiculares. ${ }^{23}$ Quando os equipamentos eletrônicos são descartados diretamente na natureza, os resíduos tóxicos penetram no solo, tornando-o indevido para agricultura, pasto e moradia.

Como já visto, a obsolescência programada é um dos grandes empecilhos para o controle de lixo eletrônico no Brasil. As empresas realizam "ajustes" e melhorias pouco significativas para atualização de smartphones, televisores e demais aparelhos eletrônicos que são considerados itens essenciais na modernidade.

Isso induz à compra de um novo exemplar, seja pelo status de estar sempre atualizado ou pela quebra repentina do produto. É uma estratégia comum em sociedades capitalistas para vender mais sem se importarem com o impacto do lixo eletrônico no meio ambiente.

Pois como destaca Amaral (2010), os empresários não podem exercer

comunidades carenciadas estão mais expostas aos fatores de risco do lixo eletrônico, o que demonstra uma correlação entre os impactos desproporcionais dos processos ambientais e a ineficiência de políticas públicas e serviços de coleta de resíduos, saneamento básico e fornecimento de água potável. A injustiça ambiental é percebida pela presença de aterros e lixões localizados estrategicamente em áreas periféricas, do que em áreas de referência (cf. MARTUZZI; MITIS; FORASTIERE, 2010).

22 Considerando a pesquisa realizada pela United Nations University (UNU), em cooperação da International Telecommunication Union (ITU) e International Solid Waste Association (ISWA), o Estados Unidos está no topo da produção de lixo eletrônico, com 6.3 toneladas. Já o Brasil, apresenta o segundo lugar com 1.5 toneladas de lixo eletrônico, com baixa capacidade de coleta, quando comparado a média mundial (BALDÉ et al., 2017).

23 Os resíduos são definidos como perigosos e especiais em razão do risco de inflamabilidade, corrosividade, reatividade, toxicidade, patogenicidade, carcinogenicidade, teratogenicidade $\mathrm{e}$ mutagenicidade, apresentam significativo risco à saúde pública ou à qualidade ambiental, de acordo com lei, regulamento ou norma técnica (art. $3^{\text {a }}$, da Lei n. 2566/2015). 
a sua atividade com finalidade apenas de lucro, mas sim atuar de forma racional e ética, pesquisando e desenvolvendo novas tecnologias para o melhor reaproveitamento dos recursos naturais.

De forma similar, a população desinformada recai em negligência ao realizar o descarte do resíduo eletrônico no lixo convencional ou em céu aberto, contaminado o lençol freático e desqualificando o material para a correta reciclagem.

É importante mencionar, que as empresas ao longo dos anos foram grandes violadoras do meio ambiente, casos em que a sua atividade econômica somente gera malefícios para a coletividade. O pagamento da multa e a aplicação da pena é uma forma de inibição à prática do crime ambiental, considerando-se a dificuldade ou muitas vezes a impossibilidade de se retornar ao estado originário aquilo que degradado.

O grande problema é que a maioria das fábricas e organizações não contam com uma política de descarte e logística reversa no pós-consumo, principalmente por não aceitarem os custos elevados do compliance no monitoramento do produto desde o seu nascimento até o descarte do resíduo, o que leva o não cumprimento da PNRS.

\section{CONCLUSÃO}

O aumento do lixo em razão do descarte incorreto dos resíduos sólidos faz com que haja uma dicotomia entre as propostas de desenvolvimento sustentável e o processo de desenvolvimento econômico. É necessário pensar em novas práticas sustentáveis na elaboração dos produtos, aumentando a sua vida útil e fomentando a reciclagem dos resíduos eletrônicos.

A Política Nacional de Resíduos Sólidos (PNRS) demonstrou avanço quanto ao correto descarte dos produtos considerados nocivos ao meio ambiente. No entanto, há dificuldade de implementação, seja pela escassez de recursos públicos destinados à pesquisa e tecnologia, como também pela falta de atuação proativa da organização civil.

Diante dessa problemática, os programas de compliance são apresentados pelos experts na contenção de riscos ambientais, como um plano efetivo de monitoramento realizado pela alta administração.

Dada, a possibilidade de responsabilização e descaracterização da pessoa jurídica para o alcance do patrimônio dos sócios, considera-se que os custos da implementação do programa de compliance são necessários 
para evitar lesão ao meio ambiente e levar a efeito a responsabilização da empresa na seara administrativa, civil e criminal.

Todavia, com base nas ações judiciais contra as empresas responsáveis pelo desastre de Mariana e Brumadinho no Estado de Minas Gerais, é possível identificar que não basta a mera criação do programa de integridade, é necessário que o compliance seja efetivo, um compromisso que envolve todos os setores, cuja metodologia deve ser forma top down à gestão da empresa.

O Poder Público não consegue mais suportar sozinho a geração de riscos ambientais, devendo os demais atores sociais (empresas, entidades não governamentais e sociedade) trabalharem de forma cooperada e comprometida, buscando técnicas que permitam a logística reversa dos componentes eletrônicos, além de implementar canais de denúncias para prevenção de crimes ambientais.

\section{REFERÊNCIAS}

ALVES, J. A. B.; KNOREK, R. O desenvolvimento regional sob a ótica da sustentabilidade: uma reflexão sobre a economia e o meio ambiente. Ágora: Revista de Divulgação Cientifica, Mafra, v. 17, n. 2, p. 13-23, 2010.

AMARAL, A. C. N. Cooperação e responsabilidade do setor empresarial na reciclagem do lixo eletrônico. Revista FMU Direito, São Paulo, ano 24, n. 34 , p. $18-28,2010$.

ANTUNES, P. B. Dano ambiental: uma abordagem conceitual. 2. ed. São Paulo: Atlas, 2015.

BALDÉ, C. P. et al. The Global E-waste Monitor 2017: quantities, flows, and resources. Genève: International Telecommunication Union, 2017. Disponível em: <https://www.itu.int/en/ITU-D/Climate-Change/ Documents/GEM\%202017/Global-E-waste\%20Monitor\%202017\%20. pdf>. Acesso em: 2 abr. 2019.

BECK, U.; BECK-GERNSHEIM, E. Generación global. Barcelona: Paidós, 2008.

BECK, U.; GIDDENS, A.; LASH, S. Modernização reflexiva: política, tradição e estética na ordem social moderna. 2. ed. São Paulo: Universidade Estadual Paulista, 2012. 
BEDRAN, K. M.; MAYER, E. A responsabilidade civil por danos ambientais no direito brasileiro e comparado: teoria do risco criado versus teoria do risco integral. Veredas do Direito, Belo Horizonte, v.10, n.19, p. 45-88, jan./jun. 2013.

BLANCHET, L. A.; COSTA JUNIOR, A. Desenvolvimento e sustentabilidade na geração de energia elétrica. Revista Jurídica Eletrônica Direito, Sociedade e Desenvolvimento, Três Rios, v. 5, p. 1-12, 2018.

BRASIL. Presidência da República. Casa Civil. Subchefia para Assuntos Jurídicos. Lei n. 3.071 de $1^{\circ}$, de janeiro de 1916. Código Civil dos Estados Unidos do Brasil. Brasília, DF: Presidência da República, 1916. Disponível em: <http://www.planalto.gov.br/ccivil_03/leis/13071.htm>. Acesso em: 3 abr. 2019.

BRASIL. Presidência da República. Casa Civil. Lei n. 10.406, de 10 de janeiro de 2002. Institui o Código Civil. Brasília, DF: Presidência da República, 2002. Disponível em: <http://www.planalto.gov.br/ccivil_03/ leis/2002/110406.htm>. Acesso em: 3 abr. 2019.

BRASIL. Supremo Tribunal Federal. Ministro Celso de Melo vota pela condenação de três dirigentes do Banco Rural. Notícias STF, 6 set. 2012. Disponível em: <http://www.stf.jus.br/portal/cms/verNoticiaDetalhe. asp?idConteudo=217450>. Acesso em: 5 mar. 2019.

BRASIL. Senado Federal. Rumo a 4 bilhões de toneladas por ano. Revista Em Discussão!, ano 5, n. 22, set. 2014. Disponível em: <http:// www.senado.gov.br/noticias/jornal/emdiscussao/residuos-solidos/materia. html?materia=rumo-a-4-bilhoes-de-toneladas-por-ano.html>. Acesso em: 10 mar. 2019.

CAPPELLI, S. Ação Civil Pública Ambiental: a experiência brasileira, análise de jurisprudência. Revista do Ministério Público (Rio Grande do Sul), Porto Alegre, n. 52, p. 279-310, jan./abr. 2004.

CARDOSO JR, J. C. Estado, planejamento e políticas públicas: o Brasil em desenvolvimento - um olhar à luz do debate em curso no Ipea ao longo do triênio 2008-2010. In: CARDOSO JR, J. C.; SIQUEIRA, C. H. R. (Orgs.). Complexidade e desenvolvimento. Brasília: Ipea, 2011. p. 33-48.

CELEPAR - TECNOLOGIA DA INFORMAÇÃO E COMUNICAÇÃO DO PARANÁ. Celepar coleta 500 quilos de lixo eletrônico por ano. Curitiba: Celepar, 2018. Disponível em: <http://www.celepar.pr.gov.br/ 
Noticia/Celepar-coleta-500-quilos-de-lixo-eletronico-por-ano>. Acesso em: 10 mar. 2019.

CERATTI, M. K. Lixo eletrônico: um mercado com potencial milionário. El País, 18 fev. 2017. Disponível em: <https://brasil.elpais.com/ brasil/2017/02/18/politica/1487418470_101918.html>. Acesso em: 12 mar. 2019.

CHAMBERS, J. Q.; ARTAXO, P. Biosphere-atmosphere interactions: deforestation size influences rainfall. Nature Climate Change, v. 7, p. 175$-176,2017$.

CMSJP - CÂMARA MUNICIPAL DE SÃO JOSÉ DOS PINHAIS. $29^{a}$ Sessão Ordinária do $1^{\circ}$ Periodo Legislativo de 2015, em 26 de maio de 2015. Disponível em: <http://www.cmsjp.pr.gov.br/2015/05/26/29\%C2\%AAsessao-ordinaria- $\%$ E2\%80\%93-1\%C2\%BA-periodo-de-2015/>. Acesso em: 1 maio 2019.

COLOMBO, S.; FREITAS, V. Da teoria do risco concreto à teoria do risco abstrato na sociedade pós-industrial: um estudo da sua aplicação no âmbito do direito ambiental. Argumenta Journal Law, Jacarezinho - PR, Brasil, n. 23. p. 207-231, 2016.

DOMINGOS, I. M.; VEIGA, F. S. Considerações acerca do impacto ambiental, política de descarte de resíduos e a responsabilidade empresarial no pós-consumo. In: MIRANDA GONÇALVES, R.; VEIGA, F. S.; PORTELA, I. (Orgs.). Paradigmas do Direito Constitucional Atual. Barcelos: Instituto Politécnico do Cávado e do Ave, 2017. p. 253-264.

ECHEGARAY, F. Consumer's reactions to product obsolence in emerging markets: the case of Brasil, Journal of Cleaner Production, p. 1-13, 2015.

EEA - EUROPEAN ENVIRONMENT AGENCY. Waste recycling. Copenhagen: EEA, 2016. Disponível em: <https://www.eea.europa.eu/ data-and-maps/indicators/waste-recycling-1/assessment $>$. Acesso em: 19 mar. 2019.

GÓMEZ-JARA DÍEZ, C. La responsabilidad penal del Compliance Officer. In: Jornada: la responsabilidad penal de la empresa y los programas de compliance. Madrid: Fundación Ramón Areces, 2015.

GUARAGNI, F. A.; CHIAMULERA, A. Autorresponsabilidade penal da pessoa jurídica em crimes ambientais: aspectos práticos da atuação do Ministério Público. 2015. Disponível em: <http://www.ceaf.mppr. 
mp.br/arquivos/File/Teses_2015/FabioGuaragni_AndressaChiamulera Autorresponsabilidade_Penal_da_Pessoa_Juridica_em_Crimes_ Ambientais.pdf $>$. Acesso em: 22 mar. 2019.

GUERRA, S. Logística reversa: meio ambiente e competitividade. São Paulo: Pearson Prentice Hall, 2012.

IPEA - INSTITUTO DE PESQUISA ECONÔMICA APLICADA. Apenas $13 \%$ dos resíduos sólidos urbanos do país vão para reciclagem. Notícias, 25 jan. 2017. Disponível em: <http://www.ipea.gov.br/portal/ index.php?option=com_content\&view $=$ article\&id=29296:apenas-13-dosresiduos-urbanos-no-pais-vao-para-reciclagem \&catid=1:dirur\&directo ry $=1>$. Acesso em: 15 mar. 2019.

KHANNA, J. et al. Regional dry-season climate changes due to three decades of Amazonian deforestation. Nature Climate Change, v. 7, p. 200204, 2017.

LEE, Y. N. The world is scrambling now that China is refusing to be a trash dumping ground. $C N B C, 16$ abr. 2018. Disponível em: $<$ https://www.cnbc. com/2018/04/16/climate-change-china-bans-import-of-foreign-waste-tostop-pollution.html>. Acesso em: 15 mar. 2019.

LEITE, P. R. Logística reversa: meio ambiente e competitividade. 2. ed. São Paulo: Pearson Prentice Hall, 2009.

MACHADO, P. A. L. Direito Ambiental Brasileiro. 20. ed. São Paulo: Malheiros, 2012.

MAIELLO, A.; BRITTO, A. L. N. P.; VALLE, T. F. Implementação da Política Nacional de Resíduos Sólidos. Rev. Adm. Pública, Rio de Janeiro, v. 52, n. 1, p. 24-51, jan. 2018.

MARTUZZI, M.; MITIS, F.; FORASTIERE, F. Inequalities, inequities, environmental justice in waste management and health. European Journal of Public Health, v. 20, n, 1, p. 21-26, jan. 2010.

MELLO, D. Lixões continuam a crescer no Brasil, mostra levantamento. $E B C, 14$ set. 2018. Disponível em: <http://agenciabrasil.ebc.com.br/ geral/noticia/2018-09/1ixoes-continuam-crescer-no-brasil-mostralevantamento>. Acesso em: 12 mar. 2019.

NOBRE, C. A. et al. Land-use and climate change risk in the Amazon and the need of a novel sustainable development paradigm. Proceedings of the 
National Academy of Sciences of the United States of America, v. 113, n. 39, p. 10759-10768, sep. 2016.

ONU - ORGANIZAÇÃO DAS NAÇÕES UNIDAS. Agenda 2030 para o desenvolvimento sustentável. Disponível em: <https://nacoesunidas.org/ tema/agenda2030/>. Acesso em: 15 mar. 2019.

PAPANEK, V. Design for The Real World: human ecology and social change. Chicago: Academy Chicago, 2009. p. 25-28.

PARREIRAS, M. Três anos depois do rompimento da barragem do Fundação, o pesadelo continua. EM.com.br, 4 nov. 2018. Disponível em: $\quad<$ https://www.em.com.br/app/noticia/gerais/2018/11/04/interna gerais, 1002816/3-anos-apos-rompimento-da-barragem-do-fundao-opesadelo-continua.shtml>. Acesso em: 12 mar. 2019.

RODRIGUES, L. Vale diz que laudos não apontavam rompimento da barragem de Brumadinho. EBC, 12 fev. 2019. Disponível em: <http:// agenciabrasil.ebc.com.br/geral/noticia/2019-02/vale-diz-que-nao-haviarisco-de-rompimento-da-barragem-de-brumadinho $>$ Acesso em: 14 mar. 2019.

RORAIMA, Mato Grosso e Tocantins lideram queimadas na Amazônia. Portal Amazônia, 28 jun. 2018. Disponível em: <http://portalamazonia. com/noticias/rr-mt-e-to-lideram-focos-da-incendio-na-amazonia $>$. Acesso em: 10 abril. 2019.

SAAVEDRA, G. A. Reflexões iniciais sobre criminal compliance. Boletim IBCCRIM, São Paulo, ano 18, n. 218, p. 10-12, jan. 2011.

SARIS, P. B. (Org.). United States Setencing Comission. Guidelines Manual, 2016. Disponível em: <https://www.ussc.gov/sites/default/files/ pdf/guidelines-manual/2016/GLMFull.pdf>. Acesso em: 12 mar. 2019.

SLADE, G. Made to break: technology and obsolescence in America. Cambridge: Harvard University Press, 2007.

SEN, A. Sobre ética e economia. São Paulo: Companhia das Letras, 1999. SERI - SUSTAINABLE ELECTRONICS RECYCLING INTERNATIONAL. O padrão de reciclagem responsável R2. Hastings: SERI, 2014. Disponível em: <https://sustainableelectronics.org/sites/ default/files/R2-2013\%20Standard\%20\%5BPORTUGUESE\%5D.pdf>. Acesso em: 5 mar. 2019. 
SOX LAW. A guide to the Sarbanes-Oxley Act 2002. Lake Forest: AddisonHewitt Associates, 2002 Disponível em: <http://www.soxlaw.com/>. Acesso em: 18 mar. 2019.

TJ-MG. Apelação Civil 10687140021258001 MG. Ação Civil Pública. Relator: Versiani Penna, Data de Julgamento: 08.11.2018, Data de Publicação: 14/11/2018.

VERÍSSIMO, C. Compliance: incentivo à adoção de medidas anticorrupção. São Paulo: Saraiva, 2017.

WEDY, G. Breves considerações sobre a responsabilidade civil ambiental. 2018. ConJur, 1 set. 2018. Disponível em: <https://www.conjur.com. br/2018-set-01/ambiente-juridico-breves-consideracoes-responsabilidadecivil-ambiental>. Acesso em: 1 maio 2019.

WENTZEL, M. Desastre deve ser investigado como crime, diz ONU. $B B C, 28$ jan. 2019. Disponível em: <https://www.bbc.com/portuguese/ brasil-47027437>. Acesso: 28 jan. 2019.

Artigo recebido em: 22/05/2019.

Artigo aceito em: 29/07/2019.

\section{Como citar este artigo (ABNT):}

DOMINGOS, I. M. N.; BLANCHET, L. A. Programas de compliance e a responsabilidade da empresa na fase de pós-consumo de lixo eletrônico. Veredas do Direito, Belo Horizonte, v. 16, n. 35, p. 269-295, maio/ago. 2019. Disponível em: <http://www.domhelder.edu.br/revista/index.php/ veredas/article/view/1547>. Acesso em: dia mês. ano. 